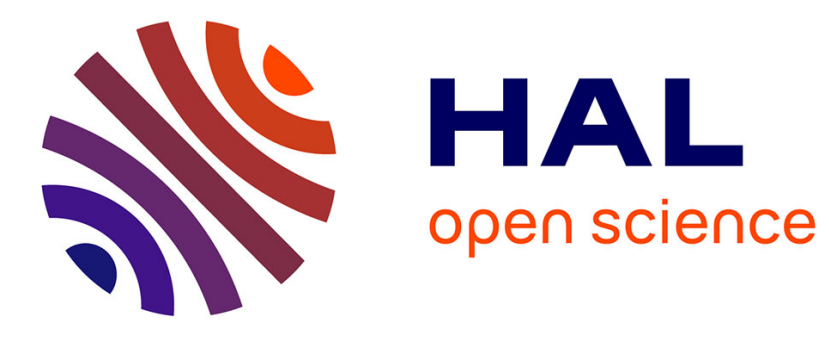

\title{
Identification of a novel mutations c.80 + 3del4 and *c.6589delA in Slovak HBOC families
}

\author{
Michal Konecny, Miriam Vizvaryova, Katarina Zavodna, Regina Behulova, \\ Maria Gerykova Bujalkova, Tomas Krivulcik, Frantisek Cisarik, Juraj Kausitz, \\ Eva Weismanova
}

\section{To cite this version:}

Michal Konecny, Miriam Vizvaryova, Katarina Zavodna, Regina Behulova, Maria Gerykova Bujalkova, et al.. Identification of a novel mutations c. $80+3 \mathrm{del} 4$ and ${ }^{*}$ c.6589delA in Slovak HBOC families. Breast Cancer Research and Treatment, 2008, 119 (1), pp.233-237. 10.1007/s10549-008-0244-6 . hal00486602

\section{HAL Id: hal-00486602 https://hal.science/hal-00486602}

Submitted on 26 May 2010

HAL is a multi-disciplinary open access archive for the deposit and dissemination of scientific research documents, whether they are published or not. The documents may come from teaching and research institutions in France or abroad, or from public or private research centers.
L'archive ouverte pluridisciplinaire HAL, est destinée au dépôt et à la diffusion de documents scientifiques de niveau recherche, publiés ou non, émanant des établissements d'enseignement et de recherche français ou étrangers, des laboratoires publics ou privés. 


\title{
Identification of a novel mutations $B R C A 1 * \mathrm{c} .80+3 \mathrm{del} 4$ and $B R C A 2 *$ c.6589delA in Slovak HBOC families
}

\author{
Michal Konecny · Miriam Vizvaryova $\cdot$ Katarina Zavodna $\cdot$ Regina Behulova \\ Maria Gerykova Bujalkova · Tomas Krivulcik · Frantisek Cisarik • \\ Juraj Kausitz $\cdot$ Eva Weismanova
}

Received: 27 September 2008/Accepted: 30 October 2008/Published online: 15 November 2008

(C) Springer Science+Business Media, LLC. 2008

\begin{abstract}
Mutations in the BRCA1 and BRCA2 genes account for the majority of hereditary breast ovarian cancer (HBOC) cases. However, after BRCA1 and BRCA2 screening still the most HBOC cases remain negative for any mutational event. Accordingly, in these cases raises the relevance to analyze the unusual $B R C A 1 / 2$ variants of uncertain clinical significance. Complex RNA/cDNA analysis may constitute the solution and help to interpret the HBOC syndrome in the family. In our study we analyzed the novel, to our knowledge, not yet published mutations identified in Slovak HBOC families, c. $80+3$ del4 (IVS2 + 3delAGTC) in BRCAl gene and mutation c.6589delA (6817delA) in BRCA2 gene. To determine the effect of the $B R C A 1$ mutation, we applied different approaches: segregation analysis of mutation with disease, presence in the set of unaffected controls and finally RNA/cDNA BRCAI analysis. Novel BRCA2 mutation was determined performing direct sequencing analysis. In conclusion, considering the results from all used techniques we approved the
\end{abstract}

M. Konecny $(\bowtie) \cdot$ M. Vizvaryova $\cdot$ K. Zavodna $\cdot$ J. Kausitz . E. Weismanova

Department of Clinical Genetics, St. Elizabeth Cancer Institute, Heydukova 10, 81250 Bratislava, Slovakia

e-mail: mkonecny@ousa.sk

R. Behulova

Institute of Medical Biology and Genetics, Faculty of Medicine, Comenius University, Bratislava, Slovakia

K. Zavodna · M. Gerykova Bujalkova · T. Krivulcik Laboratory of Cancer Genetics, Cancer Research Institute of Slovak Academy of Sciences, Bratislava, Slovakia

F. Cisarik

Department of Clinical Genetics, Hospital and Clinic, Zilina, Slovakia mentioned mutations as seriously pathogenic and disease causing with clear effect on the onset of HBOC syndrome.

Keywords BRCA1 - BRCA2 - Novel mutation ·

Splicing mutation $\cdot$ Hereditary breast ovarian cancer (HBOC) - Slovak population

\section{Introduction}

Germ-line mutations in $B R C A 1$ and $B R C A 2$ are responsible for the most of the hereditary breast and ovarian cancer (HBOC) cases, thus account for approximately $15-20 \%$ of breast and $60-80 \%$ of breast and ovarian cancer cases [1]. However, in all tested populations, the frequency of identified BRCA1 and BRCA2 mutations in high-risk HBOC families was consistently lower than predicted by linkage analysis [2].

Although, the part of the BRCA1/BRCA2 negative cases (5-10\%) may be assigned to the presence of PCR undetectable large genomic rearrangements (LGRs) [3], still the most HBOC cases remain negative for any mutational event.

Generally, germ-line mutations identified in $B R C A$ genes may be divided according to their clinical significance into three groups: (1) disease-causing, pathogenic mutations (clear clinical consequence); (2) single nucleotide polymorphisms (SNPs), mostly missense or synonymous mutations (no clinical consequence) and (3) variants of uncertain significance (unknown clinical consequence) [4].

Intronic uncertain variants may lead to the aberrant splicing through affecting the intron consensus sequences at the splice sites, or through creating ectopic splice sites. Missense exonic uncertain variants may intervene the exonic splice enhancer (ESE) sites, sequences localized 
within exons that promote and regulate the splicing of the appropriate transcript [5] or influence the functions of protein domains.

Molecular evaluation of variants of uncertain significance is very demanding and a variety of approaches for their classification have been reported. These include RNA/ cDNA analysis, co-segregation of the variant with disease in the family history, $\mathrm{LOH}$ in the tumors, the occurrence in the set of unaffected controls, co-occurrence of the variant with pathogenic mutation in the same gene, prediction based on the amino acid conservation and position in the protein, biochemical and structural assays and mouse models [6].

Recently, the splicing studies indicate that up to $70 \%$ of human genes may have alternatively spliced mRNA isoforms [7]. Thus far, three protein products of wild type $B R C A 1$ alternative splice variants have been identified (BRCAl-wt, BRCAl-del11B，BRCAl-IRIS) at different levels [8]. However recently Lixia et al. [9] reported nine $B R C A 1$ alternative variants in breast cancer cell line, indicating that BRCAl may have unexpectedly other splice variants.

Herein, we report two novel, to our knowledge, not yet published mutations detected in $B R C A 1$ and $B R C A 2$ genes. We demonstrate the disease causing effect of novel BRCAI mutation c. $80+3$ del 4 using the combination of segregation analysis and RNA/cDNA analysis. Concurrently, we show clear pathogenic effect of novel BRCA2 frame-shift mutation c.6589delA creating stop codone leading to truncated protein.

\section{Patients and methods}

\section{BRCA1 HBOC family}

Healthy proband (III:2) from HBOC family was analyzed for presence of mutations in BRCAl gene. DNA was extracted from whole blood using QIAamp DNA Mini Kit (Qiagen). PCR reaction was performed using primers specific for the coding sequence and exon-intron boundaries of all $B R C A l$ exons, which were analyzed using sequencing analysis with BigDye terminator v1.1 cycle sequencing kit on ABI 3130 genetic analyzer (applied biosystems). This analysis revealed the novel mutation c. $80+3$ del4, which constitute the deletion of AGTC nucleotides three bases after exon 2, after the GT splice signal.

Patient II:2 (Fig. 1a), mother of the healthy proband (III:2) died from ovarian cancer diagnosed at the age of 66 years. Patient II:3 died from ovarian cancer diagnosed at the age of 52 years. Patient I:2 died from breast cancer diagnosed at the age of 59 years and her two sisters (I:3, I:4) died from breast, respectively ovarian cancer

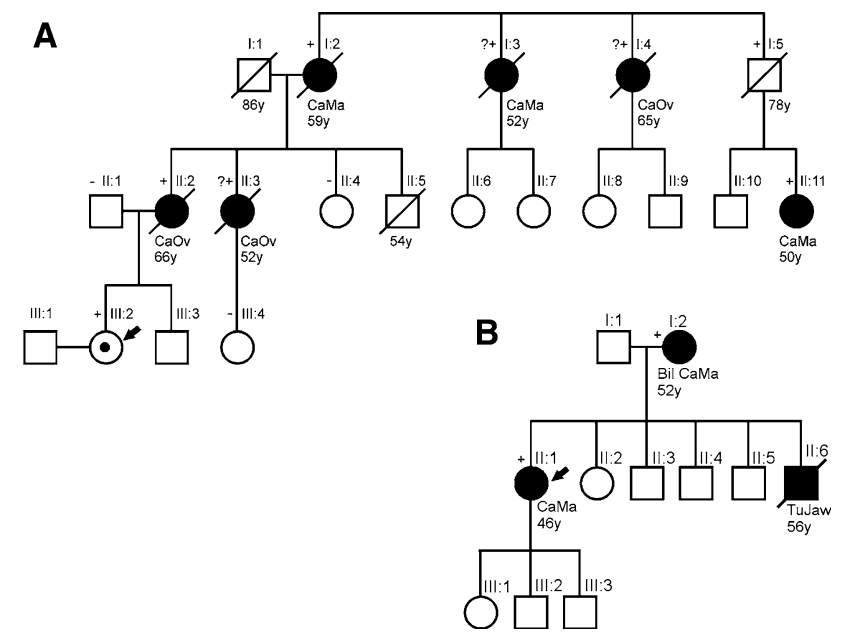

Fig. 1 a $B R C A 1$ family history; b $B R C A 2$ family history. The abbreviations: $\mathrm{CaOv}$, ovarian cancer; $\mathrm{CaMa}$, breast (mammary) cancer; $y$, age at diagnosis; +, presence of mutation; ?+, suspected presence of mutation; -, mutation not detected; arrow, primarily analyzed proband

diagnosed at the age of 52 and 65 years. Patient II: 11 had diagnosed breast cancer at the age of 50 years.

In the next step, to exclude the possible neutral, or uncertain significance of the variant c. $80+3$ del4, we analyzed the set of 200 unaffected controls using sequencing analysis of exon 2 of BRCAl gene.

Peripheral blood samples with EDTA from mutation carriers III:2 and II:11 and non-carriers II:1, II:4 and III:4 were collected in two steps. In the first step, blood from III:2, II:1 and II:4 was collected, leukocytes separated and stored at $-20^{\circ} \mathrm{C}$. Alternatively, in the second step, all blood samples were collected (II:1, II:4, II:11, III:2, III:4) and before RNA isolation treated with RNAlater solution (Ambion) for longer storage at $-20^{\circ} \mathrm{C}$.

Later, total RNA was isolated using RiboPure Blood kit (Ambion) and at the end of the isolation treated to avoid DNA contamination using DNase I (Ambion) according to manufacturer's recommendations. Isolated RNA was quantified on the Nanodrop N-1000 (Thermo Scientific) and qualitatively assessed in the RT-PCR reaction of the housekeeper gene (GAPDH) using primers GAPDH-S and GAPDH-A. The concentrations of RNA samples varied from 15 to $60 \mathrm{ng} / \mu \mathrm{l}$, with purity (OD 260/280) from 1,7 to 2,0 and no RNA sample was degraded. Wild type control sample was employed with each RNA isolation.

RT-PCR and PCR reactions were performed in single tube by One-Step RT-PCR Kit (Qiagen), according to manufacturer's protocol, using cDNA BRCAl primers C1AF: $5^{\prime}$-GCTGTGGGGTTTCTCAGATA-3', and C2AR: $5^{\prime}$-AAGTCTTTTGGCACGGTTTC- $3^{\prime}$, amplifying the region from exon $1 \mathrm{~A}$ through exon 7 , resulting in expected fragment of length $497 \mathrm{bp}$. After cDNA amplification, the 
fragments were visualized by the agarose gel (2\%) electrophoresis. The sequence of amplified PCR fragment was identified using direct sequencing analysis in both forward and reverse directions.

\section{BRCA2 HBOC family}

Patient with breast cancer diagnosed at the age of 46 years passed the analysis of all exons of BRCAl gene, which was based on SSCP analysis and sequencing of atypical PCR fragments. BRCAl analysis was finished as negative for presence of pathogenic mutation. Further the sample was analyzed for presence of mutations in BRCA2 gene, especially exons $5,6,10,11,17,20,23,25$ were diagnosed. Theoretically, pathogenic mutations in these BRCA2 exons are responsible for $89 \%$ of all $B R C A 2$ positive families in Central and Eastern Europe.

Analyzed patient had diagnosed breast cancer at the age of 46 years (II:1) (Fig. 1b). Mother (I:2) of the analyzed patient suffered bilateral breast cancer diagnosed at the age of 52 years. Brother (II:6) of the patient died from malign tumor of the face jaw at the age of 56 years. Patient has even three other healthy brothers and one healthy sister, also has one daughter and two sons.

Primarily, peripheral blood samples with EDTA from sample II:1 was collected and DNA was isolated using QIAamp DNA mini kit (Qiagen). PCR reaction was performed using primers specific for the coding sequence and exon-intron boundaries of mentioned BRCA2 exons [10], and further analyzed using sequencing analysis with BigDye terminator v1.1 cycle sequencing kit on ABI 3130 genetic analyser (applied biosystems). The presented mutation in exon 11 PCR fragment was identified reading sequencing results in both forward and reverse directions and confirmed by repeated analysis from independent sample offtake. After mutation detection, peripheral blood from sample I:2 was collected, DNA extracted and PCR of exon 11 fragment, carrying the mutation was performed.

\section{Results}

The novel BRCA1 variant c. $80+3$ del4 (IVS2 + 3delAGTC) was detected in healthy proband III:2 and in living breast/ovarian cancer patient II:11 and was not found in proband II:1, nor in proband II:4 (Fig. 1a). These results directly demonstrated that the variant is inherited from the patient II:2 and very presumably segregates with HBOC disease. Moreover, the analysis of the presence of variant c. $80+3$ del 4 in the set of 200 unaffected controls revealed no detection.

Primarily, RNA was isolated from samples III:2, II:1 and II:4 stored at $-20^{\circ} \mathrm{C}$ and not treated with RNAlater solution. The quantification of RNA showed concentrations from 15 to $32 \mathrm{ng} / \mu \mathrm{l}$. RT-PCR and PCR reaction successfully amplified 393 bp cDNA fragment of exon 1A-7 only in sample III: 2 , the carrier of the c. $80+3$ del 4 variant. The direct sequencing analysis and analysis using BLAST search [11] revealed the presence of fragment, which concerned exon 1A, 3, 5, 6, 7 however lacked exon 2 and also 6 bases (GTAAAG) from the end of exon 1A (Fig. 2c).

Secondary, the RNA analysis continued with samples II:1, II:4, II:11, III:2, III:4 treated with RNAlater solution and stored at $-20^{\circ} \mathrm{C}$. Isolated RNA was quantified (concentrations from 17 to $60 \mathrm{ng} / \mu \mathrm{l}$ ) and RT-PCR reaction was performed. In non-carriers of the c. $80+3$ del 4 variant (II: 1 , II:4, III:4) and wild-type control the presence of $498 \mathrm{bp}$ fragment was detected on the agarose gel. However, gel electrophoresis in the c. $80+3$ del 4 variant carrier samples (III:2, II:11) showed presence of minimally two fragments, shorter fragment (mutant) with stronger signal and longer one with lower signal (wild type) (data not shown).

In non-carriers and wild-type samples sequencing analysis together with BLAST search [11] showed presence of two fragments with difference of $6 \mathrm{bp}$. The first fragment consisted of exons 1A, 2, 3, 5, 6, 7; the second fragment comprised same exons but lacked 6 bases (GTAAAG) from the end of exon 1A (Fig. 2a). Sequencing analysis of cDNA from both directions (forward, reverse) in variant carriers revealed the presence of cDNA fragment comprised all exons $1 \mathrm{~A}, 2,3,5,6,7$ but also fragment consisted of exons 1A, 3, 5, 6, 7, with deleted exon 2 (Fig. 2b). The sequence analysis of cDNA fragment (exons 1A-7) from both directions confirmed that the novel BRCAl mutation c. $80+3$ del 4 results in the complete skipping of exon 2 .

The novel BRCA2 mutation c.6589delA was primarily detected in patient II:1 (Fig. 1b) performing direct sequencing analysis. Sequencing results revealed presence of double overlapping sequence from position 6817 (Genebank U43746.1) from forward direction. From reverse direction double sequence caused by deletion of $\mathrm{T}$ was localized to the same position 6817. Later the presence of deletion was also confirmed by targeted sequencing analysis of exon 11 of BRCA2 gene in patient's mother (I:2). Mutation c.6589delA was clearly localized to position 6,817, affecting codone for Thr at position 2197 in exon 11 of BRCA2 protein.

\section{Discussion}

Variants of unclassified significance (intronic or missense exonic variants) are prevalently studied only at genomic DNA level, thus their potential disease-associated effect cannot be discovered. We demonstrated, by performing the 
Fig. 2 Sequencing analysis electrophoretograms of the cDNA samples, using PCR primers [C1AF; C2AR] localized at the beginning of exon $1 \mathrm{~A}$ and at the end of exon 7. a-1 Sequencing analysis of the mutation c. $80+3$ del 4 noncarrier sample, forward direction. a-2 Sequencing analysis of the mutation c. $80+3$ del 4 non-carrier sample, reverse direction. b-1 Sequencing analysis of the mutation c. $80+3$ del 4 carrier sample, forward direction. b-2 Sequencing analysis of the mutation c. $80+3$ del 4 carrier sample, reverse direction. c-1 Sequencing analysis of the mutation c. $80+3$ del 4 carrier sample, forward direction. RNA/cDNA from sample from white-cells fraction not treated with RNAlater solution and stored at $-20^{\circ} \mathrm{C}$. c-2

Sequencing analysis of the mutation c. $80+3$ del 4 carrier sample, reverse direction. RNA/ cDNA from sample from whitecells fraction not treated with RNAlater solution and stored at $-20^{\circ} \mathrm{C}$
A-1
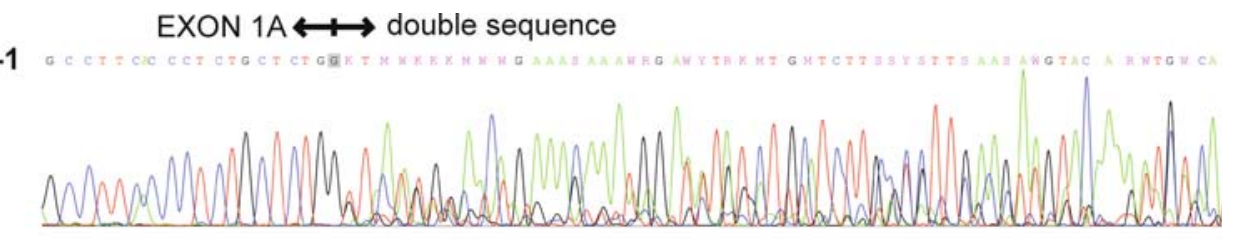

A-2

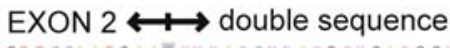

B-1

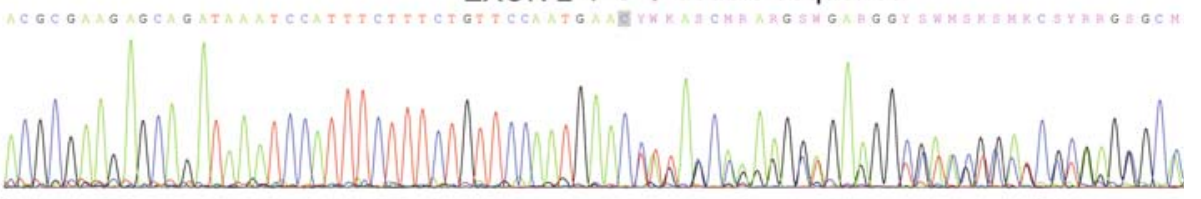

EXON 1A

B-2

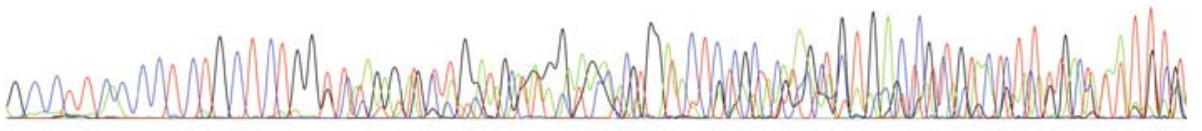

EXON $3 \longleftrightarrow$ double sequence

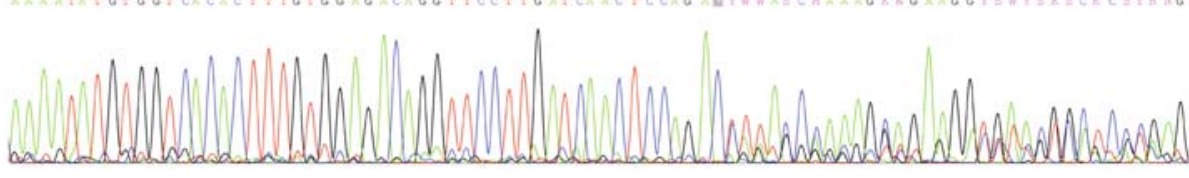

C-1
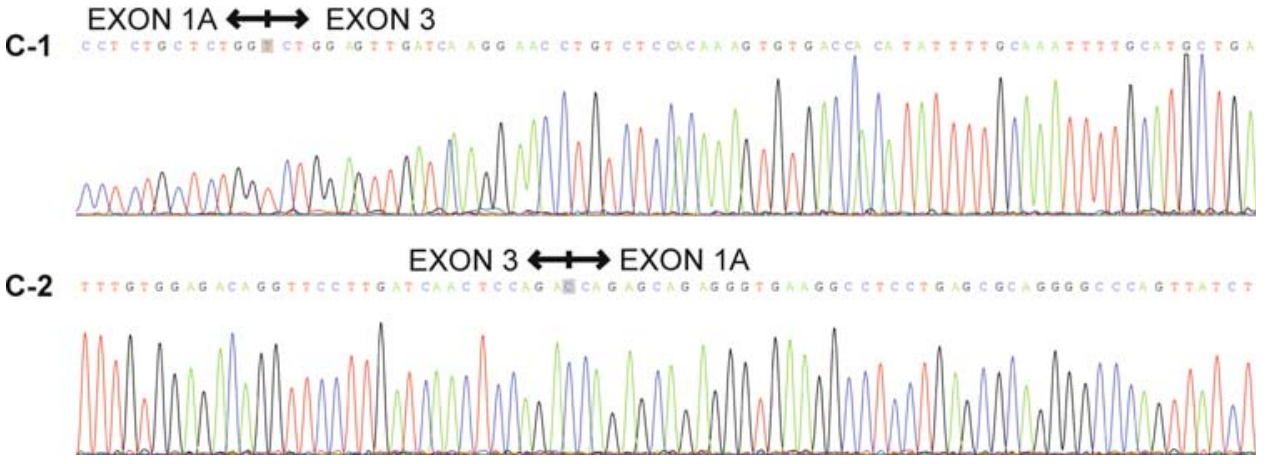

cDNA sequencing analysis, that novel intronic variant c. $80+3$ del4 (IVS2 + 3delAGTC) affects the BRCAl splicing.

The sequencing analysis of cDNA fragments was embarrassed by presence of more than one fragment (exons 1A-7 and exons 1A-7 with deletion of GTAAAG) because of alternative BRCA1 splicing. This alteration in splicing was reported by Lixia et al. [9] in breast cancer cell lines, however we detected the alterations in non-carrier and wild-type samples. We consider, that this alternative variant may represent a wild-type $B R C A 1$ isoform and may be tissue specific. The problem of $B R C A 1$ alternative splicing at the beginning of cDNA (exon 1A and 2) should be a subject of further analysis.

In c. $80+3$ del 4 mutation carrier samples treated with RNAlater solution, the cDNA sequencing analysis also revealed more fragments, however reading the sequences from both directions (forward, reverse) identified the complete deletion of exon 2. Surprisingly, in the sample of mutation carrier (white-cells fraction) stored at $-20^{\circ} \mathrm{C}$ without RNAlater solution we were able to detect single fragment consisted of exons 1A-7 with deleted exon 2 and either GTAAAG from the $3^{\prime}$ end of 1 A. These findings led us to the speculation that the fragment with deleted exon 2 might be in quantitative abundance in analyzed tissue and thus was not degraded during the storage period, while the second fragment did. Nevertheless the problems with presence of more PCR fragments, sequence analysis based on the both direction reading was able to identify the sequence of our interest, respectively the positions of deletion's start. Generally, according to the mentioned cDNA sequencing results we may summarize, that in wild type and non-carrier samples we have detected normal expected cDNA fragment comprising exons 1A-7. On the contrary, in c.80 + 3del4 mutation carrier samples we have identified cDNA fragment including exons $1 \mathrm{~A}$ and exon 3 to exon 7 , with deletion of exon 2 . We assume that in this case there might be also other fragments with or 
without GTAAAG at the end of exon $1 \mathrm{~A}$, though cannot be distinguished by used method and might be in a very low concentration.

Theoretically, the complete deletion of exon 2 excludes 47 amino acid residues, even the initial Met residue at the position 120 (according to U14680). Therefore, the translation of the aberrant protein would start at the next Met residue (ATG), which is in the position 261 in exon 5 and leads to the synthesis of C-terminally truncated BRCA1 protein. Such amino acid deletion would detached first 47 amino acid residues, together with 5 Cys residues (at amino acid positions 24, 27, 39, 44 and 47) from RING finger domain and thus would influence and presumably seriously interrupt the protein function. The RING finger domain is defined by a conserved pattern of Cys residues that is found in a wide variety of different proteins. The importance of the RING finger domain (aa residues 24-64) is supported by the observations, that the first 100 residues is the most highly conserved region in BRCAl gene [12]. The RING domains mediate interaction between BRCA1 and BARD1 proteins [13], and form heterodimer functioning as a potent E3 ubiquitin ligase [14]. In the monoubiquitination of histones appears to affect transcription and chromatin remodeling [15].

Novel frame-shift mutation c.6589delA in exon 11 of $B R C A 2$ gene in analyzed family clearly segregates with disease. Mutation renders codone for Thr at position 2197 and causes frame shift and generation of aberrant stop codone at position 2204 that leads to creation of the truncated protein. The aberrant stop codone interfere the BRC repeat region in exon 11 , which is essential for binding with RAD51 protein and thus for DNA repair. The BRCA2 protein truncation also causes absence of C-terminal conserved region basic for bound with DSS1 and DNA binding process [16].

In summary, the combination of different approaches: segregation analysis of mutation c. $80+3$ del 4 with disease within the described family, absence of the variant in the set of unaffected controls and RNA/cDNA analysis led us to the conclusion, that novel variant c. $80+3$ del4 seriously affects BRCA1 splicing and thus should be considered as disease-causing. DNA analysis based on the direct sequencing analysis of BRCA2 gene revealed novel frameshift mutation c.6589delA in exon 11 possible specific for Slovak HBOC population.

\section{References}

1. Gayther SA, de Foy KA, Harrington P, Pharoah P, Dunsmuir WD, Edwards SM, Gillett C, Ardern-Jones A, Dearnaley DP, Easton DF, Ford D, Shearer RJ, Kirby RS, Dowe AL, Kelly J, Stratton MR, Ponder BA, Barnes D, Eeles RA (2000) The frequency of germ-line mutations in the breast cancer predisposition genes BRCA1 and BRCA2 in familial prostate cancer. The Cancer Research Campaign/British Prostate Group United Kingdom Familial Prostate Cancer Study Collaborators. Cancer Res 60:4513-4518

2. Ford D, Easton DF, Stratton M, Narod S, Goldgar D, Devilee P et al (1998) Genetic heterogeneity and penetrance analysis of the BRCA1 and BRCA2 genes in breast cancer families. Am J Hum Genet 62:676-893. doi:10.1086/301749

3. De la Hoya M, Gutiérrez-Enríquez S, Velasco E, Osorio A, Sánchez de Abajo A, Vega A, Salazar R, Esteban E, Llort G, Gonzalez-Sarmiento R et al (2006) Genomic rearrangements at the BRCA1 locus in Spanish families with breast/ovarian cancer. Clin Chem 52:1480-1485. doi:10.1373/clinchem.2006.070110

4. Breast Cancer Information Core (BIC) http://research.nhgri.nih. gov/bic/. Accessed 29 Oct 2008

5. Chenevix-Trench G, Healey S, Lakhani S, Waring P, Cummings M, Brinkworth R, Deffenbaugh AM, Burbidge LA, Pruss D, Judkins T, Scholl T, Bekessy A, Marsh A, Lovelock P, Wong M, Tesoriero A, Renard H, Southey M, Hopper JL, Yannoukakos K, Brown M, Easton D, Tavtigian SV, Goldgar D, Spurdle AB, kConFab Investigators (2006) Genetic and histopathologic evaluation of BRCA1 and BRCA2 DNA sequence variants of unknown clinical significance. Cancer Res 66(4):2019-2027. doi: 10.1158/0008-5472.CAN-05-3546

6. Billack B, Monteiro AN (2004) Methods to classify BRCA1 variants of uncertain clinical significance: the more the merrier. Cancer Biol Ther 3(5):458-459

7. Kalnina Z, Zayakin P, Silina K, Linē A (2005) Alterations of premRNA splicing in cancer. Genes Chromosomes Cancer 42(4): 342-357. doi:10.1002/gcc.20156

8. Fortin J, Moisan AM, Dumont M, Leblanc G, Labrie Y, Durocher F, Bessette P, Bridge P, Chiquette J, Laframboise R, Lépine J, Lespérance B, Pichette R, Plante M, Provencher L, Voyer P, Simard J (2005) A new alternative splice variant of BRCAl containing an additional in-frame exon. Biochim Biophys Acta 1731(1):57-65

9. Lixia M, Zhijian C, Chao S, Chaojiang G, Congyi Z (2007) Alternative splicing of breast cancer associated gene BRCA1 from breast cancer cell line. J Biochem Mol Biol 40(1):15-21

10. Wagner TM, Hirtenlehner K, Shen P, Moeslinger R, Muhr D, Fleischmann E, Concin H, Doeller W, Haid A, Lang AH, Mayer P, Petru E, Ropp E, Langbauer G, Kubista E, Scheiner O, Underhill P, Mountain J, Stierer M, Zielinski C, Oefner P (1999) Global sequence diversity of BRCA2: analysis of 71 breast cancer families and 95 control individuals of worldwide populations. Hum Mol Genet 8(3):413-423. doi:10.1093/hmg/8.3.413

11. BLAST http://blast.ncbi.nlm.nih.gov/Blast.cgi

12. Meza JE, Brzovic PS, King MC, Klevit RE (1999) Mapping the functional domains of $B R C A 1$. Interaction of the ring finger domains of BRCA1 and BARD1. J Biol Chem 274(9):5659-5665. doi:10.1074/jbc.274.9.5659

13. Brzovic PS, Rajagopal P, Hoyt DW, King MC, Klevit RE (2001) Structure of a BRCA1-BARD1 heterodimeric RING-RING complex. Nat Struct Biol 8(10):833-837. doi:10.1038/nsb1001-833

14. Hashizume R, Fukuda M, Maeda I, Nishikawa H, Oyake D, Yabuki Y, Ogata H, Ohta T (2001) The RING heterodimer $B R C A 1-B A R D 1$ is a ubiquitin ligase inactivated by a breast cancer-derived mutation. J Biol Chem 276(18):14537-14540. doi:10.1074/jbc.C000881200

15. Bach I, Ostendorff HP (2003) Orchestrating nuclear functions: ubiquitin sets the rhythm. Trends Biochem Sci 28(4):189-195. doi:10.1016/S0968-0004(03)00055-0

16. Jasin M (2002) Homologous repair of DNA damage and tumorogenesis: the BRCA connection. Oncogene 21:8981-8993. doi:10.1038/sj.onc.1206176 